\title{
Not so fun in the sun: An analysis of head and neck injury patterns resulting from water sports
}

\author{
Jared Johnson $^{1}$, Michael T Chung ${ }^{*}$, Jeffrey Hotaling ${ }^{1}$, Andrew Johnson ${ }^{2}$ and Andrew Fribley ${ }^{1}$ \\ ${ }^{1}$ Wayne State University, Department of Otolaryngology, Detroit, Michigan, USA \\ ${ }^{2}$ University of Colorado, Department of Otolaryngology, Aurora, Colorado, USA
}

\begin{abstract}
Background: A variety of injuries occur with participation in water sports and can frequently range from minor contusions and lacerations to serious fractures and brain bleeds. Closed head injuries, which have garnered increasing attention in recent years due to potentially long-lasting complications, especially when they occur in the developing brain, also have been noted to occur frequently.

Purpose: To estimate the incidence, demographics and injury patterns for patients presenting to the ED with injuries to the head and neck resulting from water sport activities.

Study design: Descriptive epidemiology study.

Methods: The National Electronic Injury Surveillance System (NEISS) was evaluated for head and neck injuries from water sport activities from 2014 to 2018. The database was queried for "Water skiing, tubing, and surfing." All age ranges were included. Relevant entries were examined for incidence, patient characteristics, location of injury, and type of injury.

Results: There were 689 relevant NEISS entries for head and neck injuries resulting from water sports from 2014-2018. The median age among those injured was 21 years old and the majority were males (64\%). The most common water sports that resulted in injury were surfing (37\%), inner tube related injuries (32\%), followed by injuries resulting from wake board use (14\%). The most common injury locations were the head (40\%), followed by the face (34\%), neck (14\%), and ear ( $8 \%)$. Lacerations were the most common type of injury reported (34\%), followed by closed head injuries (30\%). Other notable type of injuries included facial fractures (5\%) and also tympanic membrane perforations (3.7\%). There was also a nearly $1 \%$ rate of reported intracranial bleeds among those injured.
\end{abstract}

Conclusion: A large number of reported water sport injuries were closed head injuries that occurred in young adults. These types of injuries have been shown to have long-term detrimental effects in the developing brain. This necessitates the need for greater emphasis on head protection during water sports, something that, at this current time, is grossly under-utilized. In addition, patients participating in water sports suffered from a variety of head and neck traumas including facial laceration, fractures, and tympanic membrane perforations.

Clinical relevance: This study will also hopefully also assist health care providers when examining and treating patients that present with head and neck injuries related to water sport activities.

What is known about the subject: While millions enjoy the thrill of water sports each year, these activities have been noted to pose significant risks for injury.

What this study adds to existing knowledge: Given the previously documented risks associated with these activities, this study will provide much needed information to the public on the risks associated with these activities, and also assist medical providers when caring for patients that present with these injuries.

\section{Introduction}

Each year more than 180 million Americans travel to the beach to enjoy the water, sand, and sunshine [1]. While some beachgoers are content sitting on the beach and wading in the water, others have preferred to chase the adrenaline rush that comes with the speed and excitement experienced with water sports. With advancements in boating technology over the last several decades, there has been a rise in popularity of towed water sports. While water skiing has been around for almost a century, tubing started to become increasingly popular in the 1970s [2,3]. Additionally, with the soaring popularity of snowboarding within the United States in more recent years, similar water sport versions, such as wakeboarding and knee boarding have also now risen to prominence $[3,4]$. Other water sports, such as surfing, which has a history that dates back thousands of years, remain popular in the United States, particularly in the coastal regions and Hawaii [5].
With the popularity of surfing, activities such as skim boarding and stand up paddle boarding, were developed as spinoff activities, and have become more widely practiced in recent years [6,7].

While millions enjoy the thrill of water sports each year, these activities have been noted to pose significant risks for injury [3,5]. Currently, little evidence exists with regards to injuries from water sport

${ }^{\star}$ Correspondence to: Michael T Chung, Division of Facial Plastic Surgery, Department of Otolaryngology, Wayne State University School of Medicine, 5E UHC, 4201 St Antoine, Detroit, MI 48201, USA, Tel: (313) 577-0804, Fax: (313) 577-8555, E-mail: michael.chung@wayne.edu

Key words: head and neck injuries, water sports, water skiing, inner tubing, surfing Received: June 08, 2020; Accepted: June 17, 2020; Published: June 26, 2020 
participation, especially with regards to injuries to the head and neck region. A variety of injuries occur with participation in water sports and can frequently range from minor contusions and lacerations to serious fractures and brain bleeds. Closed head injuries, which have garnered increasing attention in recent years due to potentially longlasting complications, especially when they occur in the developing brain, also have been noted to occur frequently [3].

Here we present an analysis of head and neck injuries presenting to the emergency department from 2014-2018 resulting from participation in water sports. To our knowledge, no comparable studies have been performed on the subject. The only similar studies used older data, explored only prevalence of injuries in a single activity, were limited to certain age ranges, or only included certain geographical locations [3-12]. Given the previously documented risks associated with these activities, this study will provide much needed information to the public on the risks associated with these activities, and also assist medical providers when caring for patients that present with these injuries.

\section{Methods}

The United States Consumer Product Safety Commission National Electronic Injury Surveillance System (NEISS) database was accessed on October 30, 2019. The database has been used in the past to help with establishing consumer product guidelines, initiating product recalls, and to increase public awareness of the risks associated with a variety of consumer products included within the database.

The NEISS database gathers data from the emergency departments (ED) of approximately 100 hospitals selected as a probability sample of all $5,000+$ U.S. hospitals with emergency departments. Each participating hospital has a NEISS coordinator that reviews all emergency room visits and selects those patients with injuries that are included within the NEISS database. The victim's age, gender, race, ethnicity, injury diagnosis, affected body parts, and the associated consumer product are coded for each patient. A brief descriptive narrative is also included if sufficient information is available.

The database was queried for "Water skiing, tubing, and surfing." We searched the database for the most recent five-year period, from 2014-2018. All age ranges were included. The results were then filtered to include only injuries to the head and neck region. The data was analyzed by patient age, gender, location of the injury, and the type of water sport the patient was participating in during injury. Of note, this study qualifies as nonhuman subject research and is exempted from institutional review board approval because the data is derived from a publicly available database offered by the U.S. Consumer Product Commission

\section{Results}

From 2014 through 2018 there were 689 head and neck injuries resulting from water sports that presented to NEISS participating emergency departments. This extrapolated to an estimated 6,718 associated injuries per year in 2017 (95\% CI 2,519 to 10,916), which was the most recent year available for a national estimate. The median age among the whole population was 21 years old (Table 1). The patients were grouped into clinical relevant ages including infants and toddlers $(0-5$ years old), young children (6-12 years old), adolescent (13-18 years old), young adult (19-40 years old), middle-age adult (41-65 years old), and senior adults (66+ years old). There was noted to be a progressively decreasing number of injuries with increasing age, especially in those older than 66 years old, which made up only $1.5 \%$ of the cohort (Table 1). In addition, the majority of injuries were noted during the summer months, with July being the most frequent month of injury (Figure 1).

The most common water sports that resulted in injury were surfing (37\%), followed by inner tube related injuries (34\%), and injuries from wake board use (14\%) (Figure 2). Other water sports were noted to have a much lower rate of injury in our study. The most common site of injury, regardless of what type of water sport the patient was participating in, was head injuries (40\%). This was followed by injuries to the face, which made up $34 \%$ of the injuries, neck (14\%), and ear (8\%) (Figure 3). Lacerations were the most common type of injury reported (34\%), followed by closed head injuries (30\%). Other notable

Table 1. Patient demographics of those presenting to the emergency department from 20142018 with head and neck injuries

\begin{tabular}{|c|c|c|}
\hline \multicolumn{2}{|c|}{ Demographic Variable } & Patients Injured (n, \%) \\
\hline Sex & & $440(64)$ \\
\hline & Male & $248(36)$ \\
\hline Age & Female & $7(1.01)$ \\
\hline & & $83(12)$ \\
\hline & $0-5$ & $192(27.9)$ \\
\hline & $6-12$ & $282(41)$ \\
\hline & $13-18$ & $114(16.5)$ \\
\hline & $19-40$ & $10(1.45)$ \\
\hline & $41-65$ & \\
\hline & $66+$ & \\
\hline
\end{tabular}

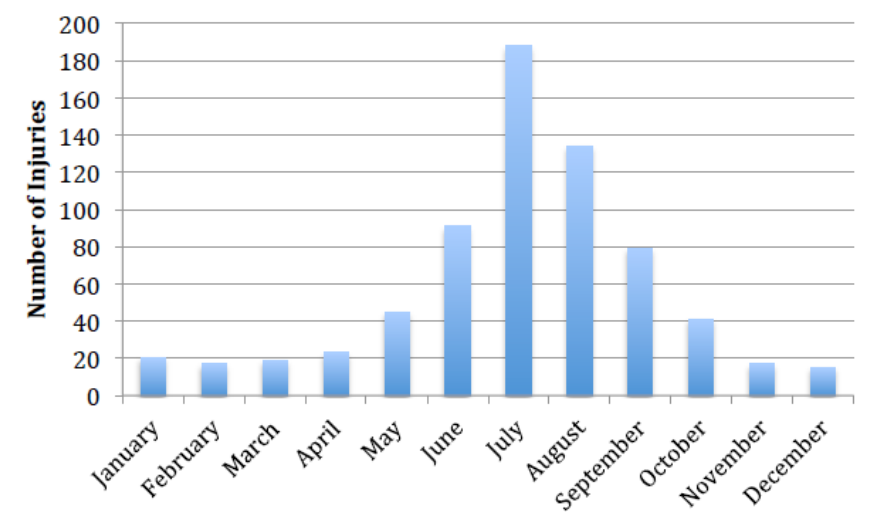

Figure 1. Number of patients presenting to the emergency department from 2014-2018 with head and neck injuries related to water sport participation.

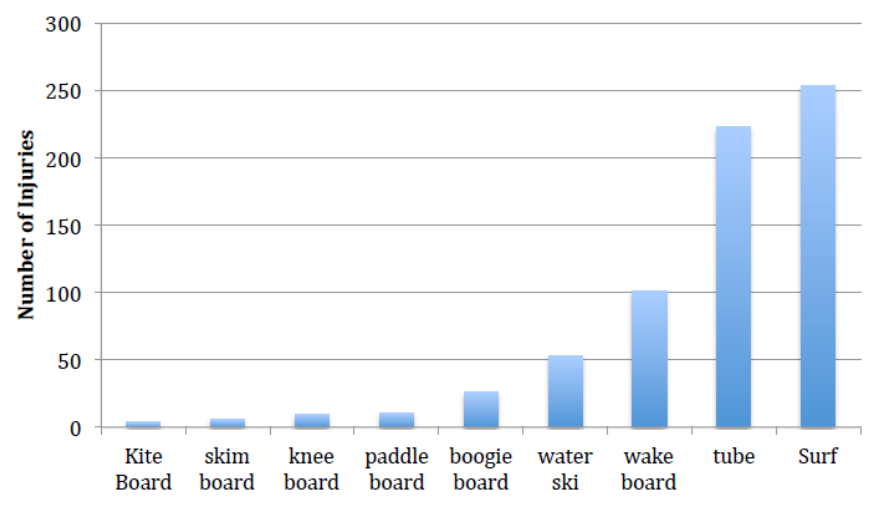

Figure 2. Most common type of water sports patients was participating in that resulted in subsequent presentation with head and neck injuries from 2014-2018. 
type of injuries included facial fractures $(5 \%)$ and also tympanic membrane perforations (3.7\%) (Figure 4 ). There was also a nearly $1 \%$ rate of reported intracranial bleeds among those injured.

\section{Discussion}

There is limited information within the literature regarding water sport related injuries, in particular those focusing on the head and neck region. Previous studies were more limited in scope and used older data [3-12]. Water sports are among the fastest growing sports and currently account for a $16 \%$ share of the global sports market, which amounted to more than $\$ 45$ billion in 2014[13]. Among the injuries that occur with water sport participation, head and neck injuries are among the most frequent and morbid, thus further investigation into common injury patterns that occur with these sports is especially warranted at this time.

Overall, head injuries were the most common location of injury followed by injuries to the face. Lacerations were the most common type of injury reported, but they were followed closely by closed head injuries (Table 2). Closed head injuries have drawn special attention in recent years throughout the sporting community due to their potentially long lasting complications, especially when they are recurrent and severe in nature $[14,15]$. There has been a strong emphasis within the sporting community in regards to preventing and quickly diagnosing closed head injuries, and athletes participating in team sports frequently

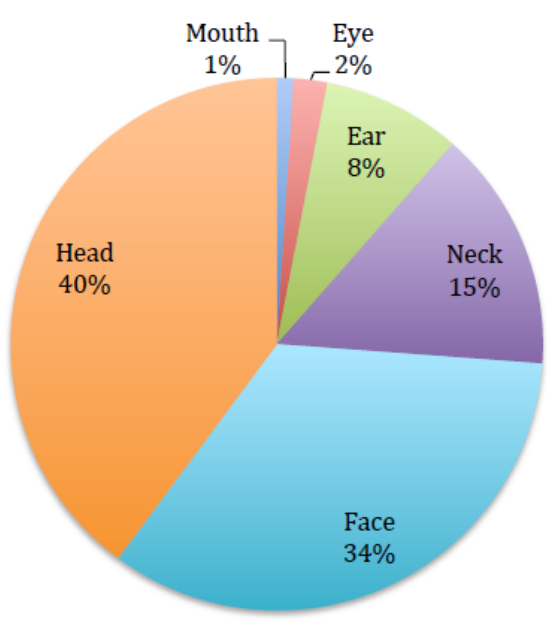

Figure 3. Distribution of primary injury location among patients presented to the emergency department in the United States following injury while participating in water sports.

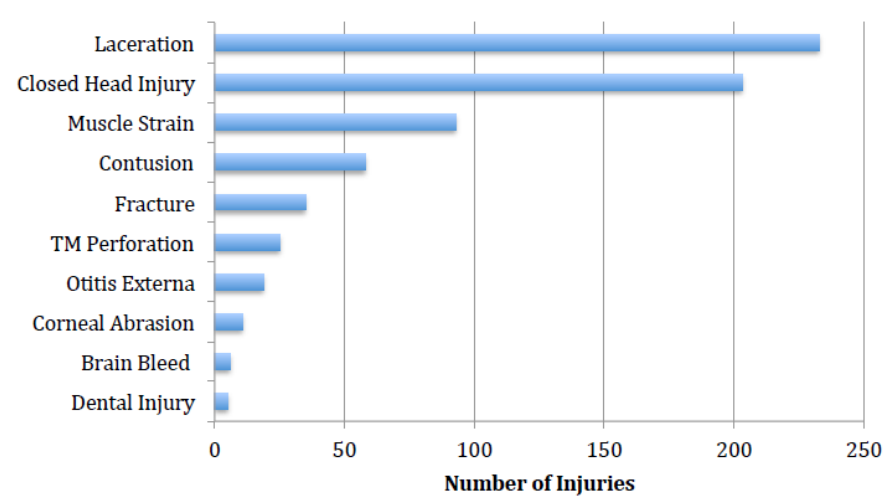

Figure 4. Most frequently occurring head and neck injuries resulting in presentation to the emergency department as a result of water sport participation.
Table 2. Injury characteristics stratified by Diagnosis and Body Part Impacted. (TM=tympanic membrane perforation)

\begin{tabular}{|l|c|c|c|c|c|c|c|}
\hline Injury Type & \multicolumn{7}{|c|}{ Body Part Injured } \\
\hline Closed head injury & Head & Face & Eyeball & Mouth & Neck & Ear & Total \\
\hline Contusion & 203 & - & - & - & - & - & 203 \\
\hline Fracture & 15 & 33 & 3 & - & 4 & 3 & 58 \\
\hline Laceration & - & 32 & - & - & 3 & - & 35 \\
\hline Dental Injury & 50 & 168 & 1 & 2 & 1 & 11 & 233 \\
\hline Muscle strain & - & - & - & 5 & - & - & 3 \\
\hline Hemorrhage & - & - & - & - & 93 & - & 93 \\
\hline Corneal abrasion & - & - & - & - & - & - & 6 \\
\hline Otitis externa & - & - & 11 & - & - & - & 11 \\
\hline TM perforation & - & - & - & - & - & 19 & 19 \\
\hline Totals & - & - & - & - & - & 25 & 25 \\
\hline
\end{tabular}

receive a prompt and thorough workup when there is concern for these injuries. Water sports typically occur in more remote locations and participants are typically only participating at a recreational level. Thus, the ability to be evaluated by medical care providers is more limited and frequently delayed in this population. In addition, the use of helmets has been more slowly adopted with water sports than other sports [16]. Teenagers and young adults, which made up most of the injuries in our study, have been noted to have a negative attitude toward helmet use, and this has also likely contributed to its slow adoption in the water sports community $[16,17]$. Given our findings though, greater emphasis on head protection would likely have the greatest impact in reducing the overall rate of injury in those participating in water sports.

Also, despite the high speeds associated with towed water sports, such as wake boarding and waterskiing, these activities were less likely than surfing to result in injury (Figure 2). Patients injured while surfing were also more likely to obtain more severe injuries such as facial fractures and closed head injuries than other water sports. Previous studies have highlighted the high rate of both lower and upper extremity injuries with surfing, but data regarding injury to the head and neck region has been limited up to this point $[11,12]$. Given the high rate of head injuries among surfers these types of injuries deserve increased recognition and greater emphasis should be placed on their prevention.

Other head and neck injuries, most notably tympanic membrane perforations were noted within the patient cohort (Table 2). These occurred most frequently in inner tube related injuries, which accounted for $64 \%$ of all tympanic membrane perforations, which was significantly more than any other type of water sport. These patients frequently presented with ear pain and otorrhea. Prior studies looking at traumatic TM perforations from water sports suggested that these injuries should initially be treated conservatively with close observation to assess for complications and persistence of the perforation [18]. In addition, the use of ofloxacin otic drops has been noted to promote a moist tympanic membrane and thus increase the rate of spontaneous closure of medium sized tympanic membrane perforations $[19,20]$. This data will hopefully allow physicians to be aware of these trends, recognize common presenting symptoms, and assist with proper treatment for these patients.

There are a variety of new water sports including paddle boarding, skim boarding, and boogie boarding, which have becoming increasingly popular over the last several years. In particular, stand up paddle board use, has grown exponentially in recent years, with participation increasing from 1.1 million in 2010 up to 2.8 million in 2014 [6]. While there were relatively few cases in our patient sample, as the popularity continues to rise, the number of injuries will continue to grow. Follow 
up studies will be beneficial in order to track the rate of injuries with these activities and to better characterize the risks associated with participation in these water sports.

There are limitations to our study, which include those inherent to the NEISS database. This includes the fact that the database utilizes 100 participating emergency departments throughout the United States. Ideally these emergency departments are representative of the entire United States, but depending on their location, especially in relation to major bodies of water for this study, could impact results. In addition, actual patients charts are not able to be reviewed and narrative description for each patient injury vary in the amount of detail provided, thus making it difficult to fully rule out coding errors in the database. Nonetheless, this study presents previously unreported data for head and neck injuries associated with water sport use. It will hopefully enable providers to better assess and treats patients presenting with water sport injuries. This study also emphasizes the need for the use of head protection in water sports, given the high rate of skull injuries. This study will also hopefully encourage the adoption of regulations by professional water sport associations with regards to head protection, and thus help promote and normalize the use of these safety measures in the general population.

\section{References}

1. Houston JR (2008) The economic value of beaches: a 2008 update. Shore and beach 76: $22-26$.

2. Banta JV (1979) Epidemiology of waterskiing injuries. West J Med 130: 493.

3. Baker JI, Griffin R, Brauneis PF, Rue III LW, McGwin Jr G (2010) A comparison of wakeboard-, water skiing-, and tubing-related injuries in the United States, 2000-2007. J Sports Sci Med 9: 92. [Crossref]

4. Carson Jr WG (2004) Wakeboarding injuries. Am J Sports Med 32: 164-173. [Crossref]

5. Klick C, Jones CM, Adler D (2016) Surfing USA: an epidemiological study of surfing injuries presenting to US EDs 2002 to 2013. Am J Sports Med 34: 1491-1496. [Crossref]

6. Furness J, Olorunnife O, Schram B, Climstein M, Hing W (2017) Epidemiology of injuries in stand-up paddle boarding. Orthop J Sports Med 5: 2325967117710759. [Crossref]
7. Sciarretta KH, McKenna MJ, Riccio AI (2009) Orthopaedic injuries associated with skimboarding. Am J Sports Med 37: 1425-1428. [Crossref]

8. Steinbrück K, Paeslack V (1980) Analysis of 139 spinal cord injuries due to accidents in water sports. Paraplegia 18: 86. [Crossref]

9. Hostetler SG, Hostetler TL, Smith GA, Xiang H (2005) Characteristics of water skiingrelated and wakeboarding-related injuries treated in emergency departments in the United States, 2001-2003. Am J Sports Med 33: 1065-1070. [Crossref]

10. Hummel G, Gainor BJ (1982) Waterskiing-related injuries. Am J Sports Med 10: 215 218. [Crossref]

11. Nathanson A, Bird S, Dao L, Tam-Sing K (2007) Competitive surfing injuries: a prospective study of surfing-related injuries among contest surfers. Am J Sports Med 35: 113-117. [Crossref]

12. Nathanson A, Haynes P, Galanis D (2002) Surfing injuries. Am J Emerg Med 20: 155 160. [Crossref]

13. "Statistics \& Research." Participation Study. Available from: www.nmma.org/ statistics/publications/participation-study.

14. Andrews TK, Rose FD, Johnson DA (1998) Social and behavioural effects of traumatic brain injury in children. Brain Inj 12: 133-138. [Crossref]

15. Mulder H, Pitchford NJ, Hagger MS, Marlow N (2009) Development of executive function and attention in preterm children: a systematic review. Dev Neuropsychol 34 393-421. [Crossref]

16. Lajunen T, Räsänen M (2001) Why teenagers owning a bicycle helmet do not use their helmets. J Safety Res 32: 323-332.

17. Lajunen T, Räsänen M (2004) Can social psychological models be used to promote bicycle helmet use among teenagers? A comparison of the Health Belief Model, Theory of Planned Behavior and the Locus of Control. J Safety Res 35: 115-123. [Crossref]

18. Rybak LP, Johnson DW (1983) Tympanic membrane perforations from water sports: treatment and outcome. Otolaryngol Head Neck Surg 91: 659-662. [Crossref]

19. Lou Z, Lou Z, Tang Y, Xiao J (2016) The effect of ofloxacin otic drops on the regeneration of human traumatic tympanic membrane perforations. Clin Otolaryngol 41: 564-570. [Crossref]

20. Lou ZC, Lou ZH, Liu YC, Chang J (2016) Healing human moderate and large traumatic tympanic membrane perforations using basic fibroblast growth factor, $0.3 \%$ ofloxacin eardrops, and Gelfoam patching. Otol Neurotol 37: 735-741. [Crossref]

Copyright: $@ 2020$ Johnson J. This is an open-access article distributed under the terms of the Creative Commons Attribution License, which permits unrestricted use, distribution, and reproduction in any medium, provided the original author and source are credited. 